\title{
New interest in maggot therapy
}

Published at www.cmaj.ca on Dec. 14, 2009

$\mathrm{P}$ amela Mitchell waited tables for 20 years. She spent copious hours on her feet. But diabetic foot ulcers put an end to that. A decade ago, when she was 47 , surgery on her left foot left a hole $2.54 \mathrm{~cm}$ deep. The wound became infected and her doctors said they had to amputate. Mitchell suggested that, instead, they try maggot therapy. Initially reluctant, her doctors agreed.

"They only did it to prove me wrong," says Mitchell, from Akron, Ohio. "I ended up proving them wrong."

After 10 sessions, the wound was gone. Now a patient advocate for the therapy, Mitchell wants more doctors to consider maggots for nonhealing wounds. She also wants more patients to realize that, since 2004, the United States Food and Drug Administration has endorsed maggot therapy for treating foot ulcers, bed sores and postsurgical wounds.

"I'd like to go on Oprah to get the word out," she says.

Though not mainstream, larval therapy, as it is also known, has enjoyed a comeback of late. Once commonly used to combat wound infections, maggots lost favour in the 1940s with the emergence of antibiotics. Their resurgence has been attributed to the rise of antibiotic-resistant bacteria and to the need for alternative treatments for chronic wounds in aging populations. The latest indirect boost for maggot therapy came from the American Medical Association and the Centers for Medicare and Medicaid Services which, in November, 2009 clarified billing code guidelines to make it easier for patients to get reimbursed for the therapy.

Advocates for the therapy say maggots of the green bottle fly are ideal for treating wounds. Maggots secrete digestive enzymes that dissolve dead tissue, destroy bacteria and promote healing (Wound Rep Reg 2002;10:208-14).

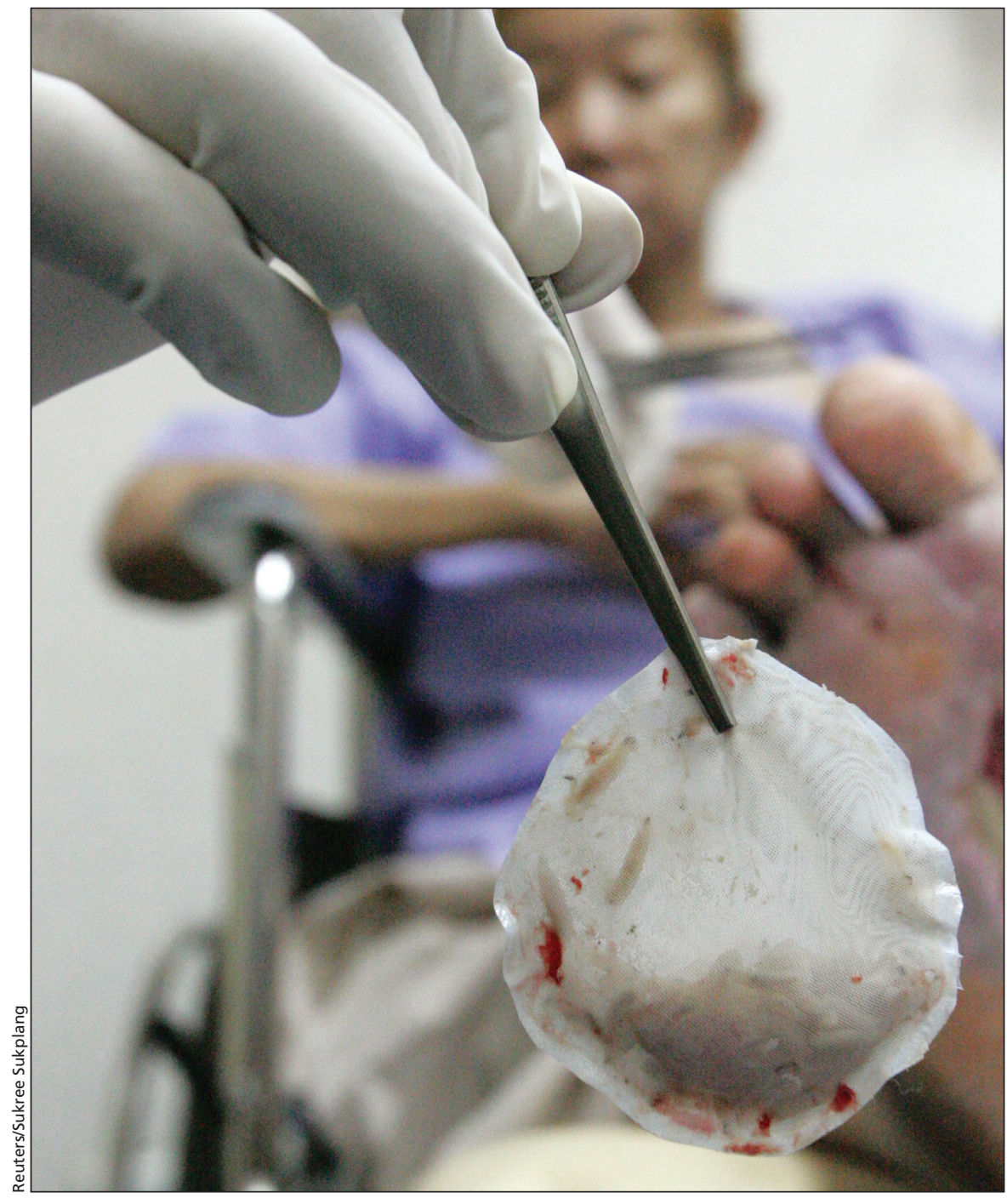

Maggots used in wound care can be poured directly into wounds or applied in an enclosed "biobag."

Though removing dead flesh via surgery is quicker, maggots, unlike scalpels, don't touch healthy tissue. They are also cheap. A treatment costs about $\$ 100$. The course of treatment depends on the size and nature of the wound but typically, three bouts of maggot therapy are required.

"Most people know it works well," says Dr. Harriet Hopf, vice-president of the Florida-based Wound Healing Society. "One problem is that there is not a huge profit opportunity in it. In wound care, as in all of medicine, if there is no profit in it, it doesn't get advertised. There are no sales reps in doctors' offices trying to sell them maggots."

Another reason maggot therapy is not more common is patient unease. Hopf says about half of the patients for which she recommends the therapy refuse. So now Hopf only suggests maggots for lower-body wounds. She tried them once on someone's trunk, but the patient could see the maggots at work and found the sight too disturbing. 
"The downside is the 'yuck' factor," says Christine Pearson, a wound clinician in British Columbia.

And it's not only patients who are disgusted by maggots. Some physicians and nurses are far from enthusiastic about the therapy, primarily for worry of maggots escaping wounds. "The potential of fleeing maggots, crawling through the patient's bed or over a hospital has caused the contempt of doctors, nurses, and patients alike," wrote German researchers (Wound Rep Reg 2007;15:756-61).

The researchers compared how well free-crawling maggots debride (remove dead tissue from) a wound compared with maggots in a closed nylon "biobag." Typically, free-crawling maggots are corralled in makeshift dressings made from mesh wire, gauze, tubes or even dental prostheses. They discovered that regardless of enclosure type, 100 maggots could debride $50 \mathrm{~g}$ of dead tissue. This corresponds to "one-third of a typical Tbone steak." Free-crawling maggots may still be preferable, though, for large irregular-shaped wounds, the researchers noted.
According to Pearson, keeping maggots contained poses little challenge. In fact, she says, patients can be taught to do it themselves at home. About 10 maggots are needed per square centimetre of application area. The wound must be covered with gauze and sealed at the edges with transparent film. After 48 hours, the maggots should be flushed out with saline.

"Then you just throw them in the household garbage," says Pearson, a registered nurse and board member of the Canadian Association of Wound Care.

Pearson says maggots shouldn't be used if wounds contain long tunnels where maggots can burrow in, making removal difficult. Also, she says, maggots might eat an exposed blood vessel if the wall of the vessel is damaged. But determining when maggot therapy is appropriate isn't the biggest challenge for wound clinicians in Canada. Since Health Canada classified medical maggots as drugs, Pearson says, the biggest challenge is getting the maggots from the United States (CMAJ 2009. DOI.10.1503/cmaj.109-3134).

Though advocates of larval therapy claim the benefits far outweigh the risks, some wound care specialists say little science exists to back those claims. Dr. Ronald Sherman, director of California-based Monarch Labs, exclusive supplier of Medical Maggots $^{\mathrm{TM}}$, recently told Live Science that maggot therapy is used by more than 1000 therapists in the US. He also said that research shows maggots save $40 \%-50 \%$ of limbs with nonhealing wounds that would have otherwise been amputated. But other researchers note that only two randomized clinical trials on the therapy have ever been published.

One of those trials found that maggots were more effective than hydrogel, which is commonly used in wound care, for treating leg ulcers ( $J$ Tissue Viability 2000;10:91-4). But critics of that trial note that only 12 patients participated and the measured outcome was debridement, not healing. A more recent study suggests that maggots, though better at debriding wounds, are not superior to hydrogel at increasing healing rates or decreasing bacteria (BMJ 2009;338: b773). — Roger Collier, CMAJ

DOI:10.1503/cmaj.109-3133

\section{Historic medical staples making comebacks}

Maggots aren't the only creepy crawlies to make a comeback in recent years. Leeches - a slimy parasite once believed to suck poison from blood and cure all manner of ailments - were a medical staple for thousands of years before falling out of vogue in the late 1800s.

Today, the bloodsuckers are back, assisting in emergency salvage therapy when surgical options fail to re-establish blood flow after a tissue graft or limb reattachment surgery.

Leeches are now commonly prescribed by Canadian surgeons to remove the pools of congested blood that interfere with circulation and can cause tissue death following surgery.

Not only do the critters suck excess blood from the grafted or replanted area, their saliva also contains a natural anticoagulant, which prevents clotting, as well as having local anesthetic and antibiotic properties.

Like maggot therapy, one obvious downside is the "yuck factor" for the patient. Nurses are also required to monitor the leeches during treatment to make sure they don't snack on healthy tissue.
Sweeter than these slimy suckers, another ancient remedy - the use of honey in wound care - is experiencing a renaissance in hospitals across the United States and Europe.

The sticky stuff has been used as a treatment for wounds since antiquity, but only recently has returned to the spotlight amid growing concern over drug-resistant superbugs.

When applied directly via a dressing, honey has been found to act as a sealant, keeping wounds moist and free from contamination. It also provides topical nutrition that is thought to promote health and tissue growth, and is a hyperosmotic agent, drawing fluid from the wound bed and killing bacteria. Additionally, honey contains an enzyme that produces the bactericide hydrogen peroxide when exposed to air.

New Zealand biochemist Peter Molan has found manuka honey can kill the toughest bacteria even when diluted 10 times, and can also prevent methicillin-resistant Staphylococcus aureus from infecting open wounds (Primary Intention: The Australian Journal of Wound Management 1998;6:148-58). — Lauren Vogel, Ottawa, Ont. 